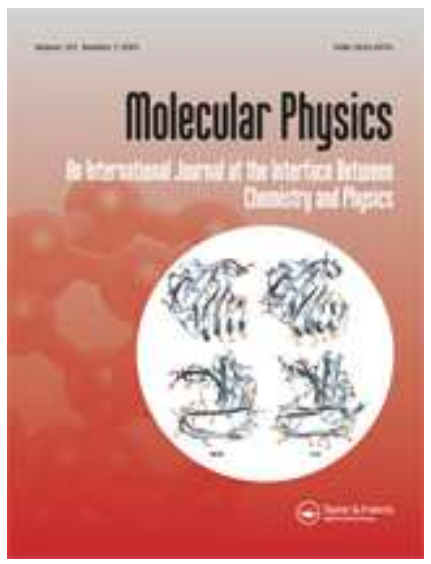

\title{
A study of thermal decomposition and combustion products of disposable polyethylene terephthalate (PET) plastic using the High Resolution Fourier Transform Infrared Spectroscopy, Selected Ion flow Tube Mass Spectrometry and Gas Chromatography Mass Spectrometry
}

\begin{tabular}{|r|l|}
\hline Journal: & Molecular Physics \\
\hline Manuscript ID: & TMPH-2008-0043.R1 \\
\hline Danuscript Type: & Full Paper \\
\hline Author: & 13-Mar-2008 \\
\hline Complete List of Authors: & $\begin{array}{l}\text { Sovová, Kristına; Academy of Sciences of the Czech Republic, J. } \\
\text { Heyrovský Institute of Physical Chemistry } \\
\text { Ferus, Martin; Academy of Sciences of the Czech Republic, J. } \\
\text { Heyrovský Institute of Physical Chemistry } \\
\text { Matulkova, Irena; J. Heyrovsky Institute of Physical Chemistry, } \\
\text { Chemical Physics } \\
\text { Španil, Patrik; Academy of Sciences of the Czech Republic, J. } \\
\text { Heyrovský Institute of Physical Chemistry } \\
\text { Dryahina, Kseniya; Academy of Sciences of the Czech Republic, J. } \\
\text { Heyrovský Institute of Physical Chemistry } \\
\text { Dvoøák, Otto; Fire Technical Institute } \\
\text { Civis, Svatopluk; J. Heyrovsky Institute of Physical Chemistry, } \\
\text { Chemical Physics }\end{array}$ \\
\hline Keywords: & $\begin{array}{l}\text { Polyethylene terephthalate, Combustion, High Resolution FTIR } \\
\text { Spectroscopy, GC-MS, SIFT MS }\end{array}$ \\
\hline \hline
\end{tabular}




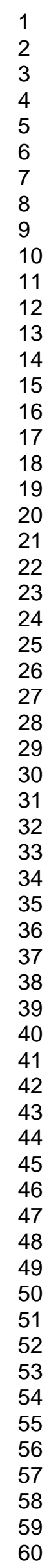

\section{$\$$ Manuscript Central}

URL: http://mc.manuscriptcentral.com/tandf/tmph 
A study of thermal decomposition and combustion products of disposable polyethylene terephthalate (PET) plastic using the High Resolution Fourier Transform Infrared Spectroscopy, Selected Ion flow Tube Mass Spectrometry and Gas Chromatography Mass Spectrometry 


\title{
A study of thermal decomposition and combustion products of disposable polyethylene terephthalate (PET) plastic using the High Resolution Fourier Transform Infrared Spectroscopy, Selected Ion flow Tube Mass Spectrometry and Gas Chromatography Mass Spectrometry
}

\author{
Kristýna Sovová $^{1}$, Martin Ferus ${ }^{1,2}$, Irena Matulková ${ }^{1}$, Patrik Španěl ${ }^{1}$, Kseniya

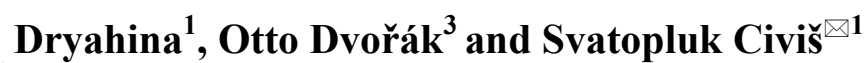 \\ ${ }^{1}$ J. Heyrovsky Institute of Physical Chemistry, Academy of Sciences of the Czech Republic, \\ Dolejškova 3, 18223 Prague 8, Czech Republic \\ ${ }^{2}$ Institute of Physics of the Academy of Sciences of the Czech Republic \\ Na Slovance 2, 18221 Prague 8, Czech Republic \\ ${ }^{3}$ Fire Technical Institute, Písková 42, 143 00, Prague 4, Czech Republic
}

\begin{abstract}
The industrial production of poly (ethylene terephthalate), PET, continues to increase and thus it is important to understand the composition of fumes resulting from its disposal as a part of incinerated waste. In this study samples of PET material were combusted in a furnace corresponding to the German standard DIN 53436 at the temperatures of $500{ }^{\circ} \mathrm{C}, 800{ }^{\circ} \mathrm{C}$ (in an air flow) and also uncontrolled burning in air. The gaseous products were then analysed using three different analytical methods: high resolution Fourier transform infrared spectroscopy (FTIR), selected ion flow tube mass spectrometry (SIFT-MS) and gas chromatography mass spectrometry (GC-MS). Carbon dioxide, methane, ethylene, acetylene, formaldehyde (methanal) and acetaldehyde (ethanal) were detected by FTIR. Water, methane, acetaldehyde, ethylene, formaldehyde, methanol, acetone, benzene, terephthalic acid, styrene (ethenylbenzene), ethanol, toluene (methylbenzene), xylene (dimethylbenzene), ethylbenzene, naphthalene, biphenyl and phenol concentrations were all quantified by both SIFT-MS and GC-MS. Additionally, the fumes resulting from uncontrolled combustion in air were analysed by FTIR which resolves the rotation-vibration structure of the absorption bands of formaldehyde (2779.90 and $2778.48 \mathrm{~cm}^{-1}$ ) and propane, which was identified from characteristic vibrations of $\mathrm{CH}_{3}$ groups at 2977.00 and $2962.00 \mathrm{~cm}^{-1}$. The spectra were compared to the reference standards.
\end{abstract}

Keywords: Polyethylene terephthalate, PET, Combustion, High Resolution FTIR Spectroscopy, GC-MS, SIFT MS

Author to whom correspondence should be addressed.

Phone: +420-266053275, Fax: +420-286591766, email: civis@jh-inst.cas.cz 


\section{Introduction}

The waste production is a fundamental problem from the environmental as well as the economic point of view. Approximately 15 million tonnes of the used plastic waste are generated every year across Europe. Of this volume, a mere $7 \%$ [1-3] is recycled and the remainder is deposited or incinerated [4]. Polyethylene terephthalate (PET, systematic name poly(oxy-1,2-ethanediyloxycarbonyl-1,4-phenylenecarbonyl)) is a highly thermally stable polymer with many uses, most frequently as packaging material for beverages [5] in the form of the well known PET bottles. The ideal way of dealing with PET waste is recycling. One of the possible recycling methods for PET is a controlled thermal degradation of PET into oligomers with olefin and carboxylic end-groups [6] including terephthalic acid whilst yielding minimal amounts of carbonaceous residue $[3,7]$. The terephthalic acid thus obtained together with other oligomers can subsequently be used in polymerisation for the production of recycled materials. Alternatively, there are two commercially available depolymerisation methods (methanolysis and glycolysis) available for PET recycling. Both of these methods reduce PET to either a monomer or the original raw materials which can be purified and subsequently re-reacted into "new" PET for use in a food-contact application, packing for detergents, cosmetics, high-quality carpets, foils, car spare parts or pillow filling for allergic persons [8].

It is worth noting that some polymers are not suitable for recycling, one example being polyethylene, PE, and sometimes for logistic and other reasons PET is not separated from the mixed communal waste. Thus the incineration of carbon-rich wastes is becoming an increasingly attractive alternative to the deposition in landfills, because as much as $90 \%$ reduction in volume [3,9] is achieved. There is a German standard DIN 53436 [10] in place concerning the combustion of PET and any other plastic materials, which sets the maximum permitted amounts of the waste products in the fumes and also gives methods for the testing 
of their toxicity.

Thermal stability and possible further applications of the degradation products of PET material have been widely-studied. Kinetic studies of PET combustion in the presence of various amounts of oxygen and with the temperatures ranging between 25 and $800{ }^{\circ} \mathrm{C}$ using TGA have recently been conducted $[4,11,12]$. Other studies have been carried out to identify the products of the thermal decomposition in the temperature range of $270-370{ }^{\circ} \mathrm{C}$ in a $\mathrm{N}_{2}$ inert atmosphere using the MALDI, ${ }^{1} \mathrm{H}$ and ${ }^{13} \mathrm{C}$ NMR methods [13]. Infrared spectroscopy has previously been used to study the products of PET thermal degradation [14] and also to study the hydro-thermal degradation under higher pressure [7,15]. Recently, PET degradation by the laser ablation was studied using AAS spectrometry, infrared spectroscopy, Gel Permeation Chromatography (GPC) and electron microscopy methods [16]. In one interesting experiment, PET material was also irradiated with $\mathrm{Ar}^{+}$ions and studied using the Rutherford Backscattering (RBS) and Elastic Recoil Detection (ERD) techniques [17].

High-resolution Fourier Transform Infrared (FTIR) spectroscopy has not so far been exploited to study the products of PET thermal decomposition and combustion. Therefore, this paper presents the results of high-resolution FTIR characterisation of these products, paving the way for wider research into the degradation of other polymers. The same samples were also studied using selected ion flow tube mass spectrometry, SIFT-MS. This mass spectrometry method is based on the chemical ionisation in a flow tube and is chiefly suitable for absolute quantifications of trace amounts of volatile organic compounds in air in the presence of water vapour. SIFT-MS has been used in various fields of research [18] but this is the first time it has been utilised to study products of polymer combustion. The main objective of this study was to compare the products of thermal decomposition of PET at $500{ }^{\circ} \mathrm{C}$, controlled combustion at $800^{\circ} \mathrm{C}$ and fumes from uncontrolled flame in air as a simulation of a imperfect PET incineration. 


\section{Experimental}

\subsection{The thermally uncontrolled combustion of PET}

The material from a transparent PET bottle with a volume of $1.5 \mathrm{~L}$ was used for a combustion experiment mimicking burning of PET in stoves or home central heating boilers. The exact temperature of the combustion cannot be defined in this situation but it is worthy noting that the inflammation point of PET is $600{ }^{\circ} \mathrm{C}$. A PET bottle was cut into strips of $1 \mathrm{x}$ $2 \mathrm{~cm}$ in size and the weight of about $2 \mathrm{~g}$. The gaseous products generated were pumped directly into a vacuum line and trapped in a liquid nitrogen trap and later released into the FTIR absorption cell.

\subsection{The thermally controlled thermal decomposition and combustion}

For the controlled thermal decomposition and combustion experiments a sample of a polyethylene terephtalate film (“TENOLAN"), from which PET bottles are made, was used. This time, the material was thermally decomposed and combusted at two temperature $\left(500{ }^{\circ} \mathrm{C}\right.$ and $800^{\circ} \mathrm{C}$ ) in the presence of air in an apparatus corresponding to the German standard DIN 53 436. The testing apparatus was set up according to DIN 53436 (see diagram shown in Figure 1) and consisted of a quartz-glass combustion tube of $1 \mathrm{~m}$ length and $40 \mathrm{~mm}$ diameter, terminated with ball-and-socket ground joints, a quartz-glass boat of $400 \mathrm{~mm}$ length $(15+$ 1) $\mathrm{mm}$ diameter wall thickness $1.7 \mathrm{~mm}$ holding the sample and a circular furnace of $100 \mathrm{~mm}$ width encircling the tube. A motor with a helix gear moved the furnace along the tube at the speed of $1 \mathrm{~cm} / \mathrm{min}$. The temperature of the furnace was maintained by a regulation module which also controls the furnace motor. The glazed front wall enabled the direct observation of the flow of the fumes during the process. The compressed air from the laboratory mains passed through a pre-drying cartridge with crystalline $\mathrm{CaCl}_{2}$ and a general-purpose flow meter, calibrated in the desired range of flows. The air flow was regulated using a needle 
valve to a flow of $150 \mathrm{~L} / \mathrm{hr}$. Note that this flow entered the tube in the opposite direction to the furnace movement and thus the sample was always exposed to a supply of clean air. The PET samples were supported inside the quartz glass combustion tube by a quartz glass boat, and heated to the preset temperatures $500{ }^{\circ} \mathrm{C}$ and $800^{\circ} \mathrm{C}$. Resulting fumes containing the thermal decomposition and combustion products were introduced via a connecting adapter into a $5 \mathrm{~L}$ mixing vessel (placed inside a box thermostat with forced circulation) in which they were kept at $130{ }^{\circ} \mathrm{C}$.

Two samples of PET foil of $0.15 \mathrm{~mm}$ thickness were cut into 400 x $20 \mathrm{~mm}$ strips and placed inside the combustion furnace boat always in five layers. The first sample of mass $6.41 \mathrm{~g}$ was subjected to the flameless thermal decomposition at the temperature of $500{ }^{\circ} \mathrm{C}$ and the second sample of mass $6.28 \mathrm{~g}$ was combusted in flame at the temperature of $800{ }^{\circ} \mathrm{C}$. As a part of the routine protocol elementary composition of the samples was determined as: C $62.86 \% \mathrm{w} / \mathrm{w} ; \mathrm{H} 4.36 \% \mathrm{w} / \mathrm{w} ; \mathrm{N} 0.12 \% \mathrm{w} / \mathrm{w}$ and the stoichiometric ratio of weight of combusted oxygen to the weight of fuel calculated accordingly to ISO TR 9122 was $\Psi=$ 2.0928. Samples of fumes containing combustion products were taken directly from the mixing vessel into glass volumes with PTF stoppers. These glass volumes were transported and their content was analysed using FTIR, GC-MS and SIFT-MS.

\subsection{FTIR spectroscopy}

The gaseous products of the uncontrolled and controlled combustion of PET samples (at $500{ }^{\circ} \mathrm{C}, 800{ }^{\circ} \mathrm{C}$ ) were released into a vacuum line and trapped in a liquid nitrogen trap. An absorption cell was filled to the pressure of 5.5 Torr by slow re-heating of this trap. The length of the absorption cell was $36.5 \mathrm{~cm}$ and the diameter was $5 \mathrm{~cm}$. The spectra were obtained at an ambient temperature using the Bruker IFS 120 HR spectrometer in the spectral range of $500-7000 \mathrm{~cm}^{-1}$. In order to cover the near-infrared (NIR) range a halogen lamp, a 
$\mathrm{CaF}_{2}$ beam splitter and InSb detector were used and to cover the middle-IR (MIR) spectral region a glow bar source, $\mathrm{KBr}$ beam splitter and $\mathrm{HgCdTe}$ detector were applied. Fifty scans of the spectra were acquired at the resolution of $0.02 \mathrm{~cm}^{-1}$ and $0.014 \mathrm{~cm}^{-1}$ using the BlackmannHarris apodisation function.

\subsection{GC-MS}

The gas chromatograph with a mass spectrometer detector, GC-MS, an instrument used for this study was "Trace GC Ultra-DSQ II" (Thermo Electron Corporation). The parameters of the Rxi ${ }^{\mathrm{TM}} 5 \mathrm{~ms}$ (manufactured by Restek) chromatographic column were: $30 \mathrm{~m}$ x $0.25 \mathrm{~mm} \times 0.25 \mu \mathrm{m}$. The temperature of the SL/S injector was $235^{\circ} \mathrm{C}$, the liner diameter was $5 \mathrm{~mm}$ and the achieved temperature range was $37-300^{\circ} \mathrm{C}$.

Samples of gases originating from the controlled thermal decomposition and combustion in the quartz combustion furnace were taken directly from its exhaust at the end of the combustion tube. The sampling method used a $500 \mu \mathrm{L}$ gas-tight syringe preheated to $60{ }^{\circ} \mathrm{C}$. The standard method of the direct Head Space analysis was applied. The samples were dosed at $60{ }^{\circ} \mathrm{C}$. The volume of the sample dose was always $500 \mu \mathrm{L}$ for both temperatures $\left(500{ }^{\circ} \mathrm{C}\right.$ and $\left.800{ }^{\circ} \mathrm{C}\right)$. The individual peak assignments seen in the chromatographs were based on the measurements of standards and their comparison with NIST '05 Mass Spectral Libraries for Xcalibur [18].

\subsection{SIFT-MS}

Selected ion flow tube mass spectrometry, (SIFT-MS), is a technique for a simultaneous real-time quantification of several trace gases in air and exhaled breath. It relies on the chemical ionization of the trace gas molecules in air/breath samples introduced into helium carrier gas, using $\mathrm{H}_{3} \mathrm{O}^{+}, \mathrm{NO}^{+}$and $\mathrm{O}_{2}{ }^{+}$reagent (precursor). Reactions between the precursor ions and the trace gas molecules proceed for an accurately defined time, the 
precursor and product ions being detected and counted by a downstream mass spectrometer. The absolute concentrations of trace gases in single breath exhalation can be determined by SIFT-MS down to parts-per-billion (ppb) levels, obviating sample collection into bags or onto traps [19]. The calibration using chemical standards is not routinely required, as the concentrations are calculated using the known reaction rate constants and the measured flow rates and pressures [20]. For this study samples of the gaseous products of controlled decomposition and combustion were collected in $6 \mathrm{~L}$ glass vessels at the atmospheric pressure, kept at an ambient temperature of $20^{\circ} \mathrm{C}$ and introduced into the Profile 3 SIFT-MS instrument (manufactured by Instrument Science Limited, Crewe, UK) via a heated calibrated capillary and full scan mass spectra were obtained by repeated full scans for all three precursor ions. The concentrations of main compounds identified on the mass spectra were calculated from the precursor and product ion count rates, the known carrier gas and sample flow rates and flow tube pressure, according to the general method for the calculation of absolute trace gas concentrations in air from selected ion flow tube mass spectrometry data [20]. The rate coefficients were taken from the kinetic library supplied with the SIFT-MS instrument where available or estimated theoretically [19]. The accuracy of quantification in this complex mixture is estimated to be a factor of about two, $+100 \%-50 \%$ of estimated absolute error. The relative precision of the measurement, however, is better estimated at about $+/-30 \%$. Thus the results provide an order of magnitude of information about the concentrations of the main components of the thermal decomposition and combustion products in the sampled fumes.

\section{Results and Discussion}

\subsection{FTIR spectroscopy}

In the NIR and MIR spectra of fumes from the uncontrolled combustion (Figure 2), we 
successfully identified a homologous series of saturated hydrocarbons, which were assigned on the basis of stretching vibrational and rotational modes of $\mathrm{C}-\mathrm{H}$ groups of methane $\left(3019 \mathrm{~cm}^{-1}\right)$, ethane $\left(2985,2969\right.$ and $\left.2954 \mathrm{~cm}^{-1}\right)$ and propane $\left(2977\right.$ and $\left.2962 \mathrm{~cm}^{-1}\right)$; the unsaturated hydrocarbon ethene, which was verified by the existence of vibrational and rotational bands of the rocking modes of the $\mathrm{C}-\mathrm{H}$ group at $949 \mathrm{~cm}^{-1}$, and acetylene, whose stretching vibrational and rotational modes of the C-H group were observed at 3374 and $3289 \mathrm{~cm}^{-1}$ and deformation vibrational and rotational bands of the same group at $730 \mathrm{~cm}^{-1}$. The group of aldehydes was represented by acetaldehyde and formaldehyde, whose stretching vibrational and rotational modes of $\mathrm{C}-\mathrm{H}$ groups lay in the FTIR spectrum at $2715 \mathrm{~cm}^{-1}$ (acetaldehyde) and 2780 and $2778 \mathrm{~cm}^{-1}$ (formaldehyde). The above-listed analysis of the IR spectra was performed using the individual vibrational and rotational lines listed in the HITRAN database [21] and using our database in a Bruker OPUS computer program.

Spectra and the analyses of the products of thermal decomposition of PET in a quartz furnace corresponding to the DIN standard, at the temperature of $500{ }^{\circ} \mathrm{C}$ (see Figure 3a) were similar to uncontrolled combustion. Thus in the FTIR spectra of products of PET decomposed at $500{ }^{\circ} \mathrm{C}$, we have identified methane, ethane, ethyne, formaldehyde, carbon dioxide, carbon monoxide and water. Figure $3 \mathrm{~b}$ shows that the PET combustion at $800{ }^{\circ} \mathrm{C}$ (i.e. above the inflammation point) is a process of more efficient burning and the main combustion products are carbon oxides and water. Carbohydrates and aldehydes appear only in concentrations that are lower than the detection limit of our FTIR method.

The main advantage of using the high-resolution FTIR method in comparison to the more commonly used low resolution FTIR spectroscopy (resolution $1-5 \mathrm{~cm}^{-1}$ ) is that it allows resolving the detailed structure of the vibrational bands, which often overlap in the spectra of complicated gaseous mixtures. With our high-resolution method, we can for example differentiate the stretching rotation-vibration lines of $\mathrm{C}-\mathrm{H}$ bonds in propane from the 
stretching rotation-vibration lines of $\mathrm{C}-\mathrm{H}$ in methane (see Figure 4).

\subsection{GC-MS}

Table 1 contains the analytic comparison of gaseous components obtained from the thermal decomposition at a temperature of $500{ }^{\circ} \mathrm{C}$ with the combustion products obtained at $800{ }^{\circ} \mathrm{C}$. Twenty three organic molecules were identified at $500{ }^{\circ} \mathrm{C}$, and at $800{ }^{\circ} \mathrm{C}$, there were twenty one different compounds. The characteristic groups of GC-MS analysis were aromatic compounds, derivates of benzoic acid, group of phthalates, biphenyles and others. Common products such as styrene, toluene and naphthalene were found in both samples. From the relative abundance of each identified compound in the chromatograms (see Figure 5 and 6 ) it is evident that their abundance at the temperature of $800^{\circ} \mathrm{C}$ is lower than in the case of $500{ }^{\circ} \mathrm{C}$. This trend was confirmed also by SIFT-MS analysis (see the next section and Table 2 there). Exceptions were biphenyle (peak number 17) and naphthalene (peak number 13), their relative abundance was higher in the $800{ }^{\circ} \mathrm{C}$ sample.

\subsection{SIFT-MS}

An analysis of the gaseous products originating from the controlled decomposition and combustion at $500{ }^{\circ} \mathrm{C}$ and $800{ }^{\circ} \mathrm{C}$ was carried out using three precursor reagent ions $\mathrm{H}_{3} \mathrm{O}^{+}$, $\mathrm{NO}^{+}$and $\mathrm{O}_{2}^{+}$. Several compounds were identified from the characteristic ions present in the $\mathrm{H}_{3} \mathrm{O}^{+}$spectra (see Figure 7). Additionally, the spectra obtained with $\mathrm{NO}^{+}$and $\mathrm{O}_{2}^{+}$precursors were used to quantify those compounds which do not react with the $\mathrm{H}_{3} \mathrm{O}^{+}$precursors. The $\mathrm{O}_{2}^{+}$ spectra were only of a limited value because of the complexity of the mixture and overlap of multiple fragmentation patterns. This has prevented unambiguous identification of more complex organic compounds, however quantification of several hydrocarbons was possible. The compounds identified on the SIFT-MS spectra are listed in Table 2 together with the characteristic product ions and their concentrations calculated for the two temperatures. SIFT- 
MS can be also used to quantify the concentration of water vapour in the fumes [22] and the results are given in Table 2.

To illustrate how the ions observed on the spectra are related to the compounds present in the analysed gaseous mixture, we will outline the main features of ion chemistry which are involved. The $\mathrm{H}_{3} \mathrm{O}^{+}$precursor ions are known to react with unsaturated hydrocarbon alkenes $\left(\mathrm{C}_{\mathrm{n}} \mathrm{H}_{2 \mathrm{n}}\right)$ and alkynes $\left(\mathrm{C}_{\mathrm{n}} \mathrm{H}_{2 \mathrm{n}-2}\right)$ [22] and with aromatic hydrocarbons by proton transfer leading to the formation of the $\mathrm{MH}^{+}$product ions.

$$
\mathrm{H}_{3} \mathrm{O}^{+}+\mathrm{M} \rightarrow \mathrm{MH}^{+}+\mathrm{H}_{2} \mathrm{O}
$$

Such proton transfer also occurs with aldehydes, ketones, small alcohols and many other compounds, as is known from many previous studies [22]. However for styrene and biphenyl, (identified by GC-MS, see Section 3.2) there was so far no knowledge of the SIFT-MS product ions. Thus, we have carried out a quick study of the ion chemistry of these two compounds and found that proton transfer is indeed the only process occurring for both styrene and biphenyl and no fragmentation occurs. In fact all products of $\mathrm{H}_{3} \mathrm{O}^{+}$reactions identified in table 2 are protonated molecules $\mathrm{MH}^{+}$. The aromatic hydrocarbons were responsible for the following ions in the $\mathrm{H}_{3} \mathrm{O}^{+}$mass spectra: $\mathrm{m} / \mathrm{z} 79$ (benzene), 93 (toluene) and 107 (xylene, ethylbenzene) and for the ions at $\mathrm{m} / \mathrm{z}$ 78, 92 and 106 in the $\mathrm{NO}^{+}$spectra. The ions in the $\mathrm{H}_{3} \mathrm{O}^{+}$mass spectra at $\mathrm{m} / \mathrm{z} 31$ and $49\left(\mathrm{MH}^{+} \cdot \mathrm{H}_{2} \mathrm{O}\right)$ are due to the presence of formaldehyde and the ions at $\mathrm{m} / \mathrm{z} 45$ a 89 are characteristic of acetaldehyde. The ions at $\mathrm{m} / \mathrm{z}$ 89 are proton bound acetaldehyde dimers $\left(\mathrm{MH}^{+} \cdot \mathrm{M}\right)$. The ions at $\mathrm{m} / \mathrm{z} 33$ and 47 are protonated methanol and ethanol, the ions at $\mathrm{m} / \mathrm{z} 59$ and 77 correspond to acetone as is confirmed by the presence of ions at $\mathrm{m} / \mathrm{z} 88\left(\mathrm{NO}^{+} . \mathrm{M}\right)$ in the $\mathrm{NO}^{+}$spectrum.

However, it must be noted that $\mathrm{H}_{3} \mathrm{O}^{+}$ions do not transfer protons to saturated alkanes and $\mathrm{O}_{2}^{+}$precursors may be used for their identification. This is exemplified in the case of methane: 


$$
\mathrm{O}_{2}^{+}+\mathrm{CH}_{4} \rightarrow \mathrm{CH}_{3} \mathrm{O}_{2}^{+}+\mathrm{H}
$$

This reaction is unusually slow, the rate coefficient being only $5.2 \times 10^{-12} \mathrm{~cm}^{3} \mathrm{~s}^{-1}[23]$. Thus the product ions of the reaction (2) are seen in $\mathrm{O}_{2}{ }^{+}$spectra at $\mathrm{m} / \mathrm{z} 47$ as characteristic product ions of methane. Ethylene reacts with $\mathrm{O}_{2}{ }^{+}$by the charge transfer, thus forming product ion at $\mathrm{m} / \mathrm{z}$ 28.

Aromatic hydrocarbons undergo charge transfer with both $\mathrm{NO}^{+}$and $\mathrm{O}_{2}^{+}$precursors, thus forming molecular ions $\mathrm{M}^{+}$. Using a combination of $\mathrm{H}_{3} \mathrm{O}^{+}$and $\mathrm{NO}^{+}$ions was thus appropriate for the reliable quantification of aromatic hydrocarbons in the fume gas samples.

The inspection of Table 2 reveals that in general concentrations of organic products are lower at the higher combustion temperature of $800{ }^{\circ} \mathrm{C}$ than at decomposition temperature of $500{ }^{\circ} \mathrm{C}$. This conforms to the results of previous studies [4,9]. The exception to this trend is the behaviour of naphthalene and biphenyl, which are seen to be more concentrated in the products of higher temperature combustion. Also there is significantly more water vapour present in the mixture obtained at $800{ }^{\circ} \mathrm{C}$. In the present study it was not possible to quantify $\mathrm{CO}_{2}$ using SIFT-MS because the characteristic ion $\mathrm{CO}_{2} \cdot \mathrm{H}_{3} \mathrm{O}^{+}$overlaps hydrated protonated acetaldehyde at $\mathrm{m} / \mathrm{z} 63$, thus exclusion of $\mathrm{CO}_{2}$ from table 2 does not imply its absence.

\section{Conclusions}

In this study, high resolution FTIR spectroscopy was used for the first time to analyse products of PET thermal decomposition and combustion. The spectra of a series of these obtained products were measured even under the conditions where their spectral rotationvibration bands overlap. The results show that high resolution FTIR spectroscopy can hardly compete with methods based on mass detection in cases where trace amounts of heavier organic molecules are to be identified. This is because the rotation-vibration spectra of heavy molecules in their gas phase at room temperature are unresolved and their measuring requires the use of sub-Doppler techniques. On the other hand, the advantage of the FTIR 
spectroscopy is that it allows observation of a very broad spectral range and that the intensities of the vibrational bands, mainly of the light molecules (water, carbon monoxide, carbon dioxide, methane, formaldehyde etc.), provide a broad view of the thermal decomposition and combustion of PET and its degree of conversion into the final combustion products $\left(\mathrm{CO}_{2}\right.$ and $\left.\mathrm{H}_{2} \mathrm{O}\right)$. Although only a single-pass absorption arrangement $(36.5 \mathrm{~cm})$ was used, we were able to detect small concentrations of some organic substances, such as formaldehyde and propane, in the fumes.

The main aim of this work was to compare the products resulting from uncontrolled combustion of PET (burning in stoves and home boilers) to the processes in which the physical conditions of the thermal decomposition $\left(500^{\circ} \mathrm{C}\right)$ or combustion $\left(800^{\circ} \mathrm{C}\right)$ are exactly defined and controlled. The results of this study show that uncontrolled burning in air leads to products which are similar to those from thermal decomposition in a quartz furnace at the temperature of $500{ }^{\circ} \mathrm{C}$, i.e. below the PET inflammation point of $600{ }^{\circ} \mathrm{C}$. In comparison, the products of PET combustion at $800{ }^{\circ} \mathrm{C}$ contain mainly carbon oxides, water and the heavier hydrocarbons in significantly lower concentrations. The only two cases where concentration increased at the higher temperature were biphenyle and naphthalene. This was independently indicated by both GC-MS and SIFT-MS results.

From the point of view of the analysis of volatile substances, the gas chromatography method remains the best. The combination of gas chromatography with the mass detection represents a very effective combination of separation and a highly sensitive detection technique. A wide range of aromatic and polyaromatic substances such as the group of phthalates [23] was identified using gas chromatography. Concentrations of these compounds were quantified also using SIFT-MS and the precision of this technique was sufficiently high to observe significant differences in the composition of the fumes originating from different temperatures of decomposition and combustion. 


\section{Acknowledgement}

This work was financially supported by the Grant Agency of the Academy of Sciences of the Czech Republic (Grant No. IAA400400705) and in part by Grant Agency of the Czech Republic (project number 202/06/0776). We greatly appreciate the essential technical contribution of Milan Růžička, MSc. from the Fire Technical Institute in Prague.

\section{References}

[1] B.G. Girija, R.R.N. Sailaja and Giridhar Madras, Polym. Deg. and Stab. 90, 147 (2005).

[2] Frederic Fraisse, Vincent Verney, Sophie Commereuc and Martin Obadal, Polym. Deg. and Stab. 90, 250 (2005).

[3] Takao Masuda, Yasuo Miwa, Atsushi Tamagawa, S.R. Mukai, Kenji Hashimoto and Yuichi Ikedab, Polym. Deg. and Stab. 58, 315 (1997).

[4] Ignacio Martin-Gullón, Mar Esperanza, Rafael Font, J. Anal. Appl. Pyrolysis, 58-59, 635 (2001).

[5] Franck Villain, Jean Coudane and Michel Vert, Polym. Deg. and Stab. 43, 431 (1994).

[6] Giorgie Montaudo, Concetto Puglisi and Filippo Semperi, Polym. Deg. and Stab. 42, 13 (1993).

[7] S.G. Kazarian and G.G. Martirosyan, Phys. Chem. Chem. Phys. 4, 3759 (2002). 
[8] http://www.petpower.nl/plastic-PET-bottles-and-jars/recycling/petpower.aspx\#

[9] N.A. García, M.M. Esperanza and Rafael Font, J. Anal. Appl. Pyrolysis 68-69, 577 (2003).

[10] DIN 53 436: Erzeugung thermischer Zersetzungsproducte von Werkstoffen unter Luftzufuhr und ihre toxikologische Prüfung. Teil 1. Zersetzungsgerät und Bestimmung der Versuchstemperatur (1981).

[11] Jin Yang, Rosa Miranda and Christian Roy, Polym. Deg. and Stab. 73, 455 (2001).

[12] Biswanath Saha, A.K. Ghoshal, Chem. Eng. J. 111, 39 (2005).

[13] F. Samperia, C. Puglisia, R. Alicatab and G. Montaud, Polym. Deg. and Stab. 83, 3 (2004).

[14] B.J. Holland, J.N. Hay, Polymer 43, 1835 (2002).

[15] Chris Sammon, Jack Yarwood and Neil Everall, Polym. Deg. and Stab. 67, 149 (2000).

[16] Markéta Urbanová, Jan Šubrt, Anna Galíková and Josef Pola, Polym. Deg. and Stab. 91, 2318 (2006).

[17] Vladimír Hnatowicz, Vratislav Peřina, Vladimír Havránek, Václav Voseček, Jiří Novotný, Jiř́i Vacík, Václav Švorčík, Vladimír Rybka and A Kluge, Nucl. Instr. and Meth. in Phys. Res. B 161-163, 1099 (2000).

[18] NIST/EPA/NIH Mass Spectral Library with Search Program (National Institute of Standards and Technology)

[19] Patrik Spanel, David Smith, Europ. J. Mass Spectrom. 13, 77 (2007).

[20] Patrik Spanel, Kseniya Dryahina, David Smith, Int. J. Mass Spectrom. 249, 230 (2006).

[21] The HITRAN Database, http://cfa-www.harvard.edu/HITRAN/

[22] David Smith, Patrik Spanel, Mass Spectrom. Rev. 24, 661 (2005).

[23] V.G. Anicich, An index of the literature for bimolecular gas phase cation-molecule reaction kinetics (JPL-Publication, Pasadena, 2003). 
[24] S.V. Leivadara, A.D. Nikolaou, T.D. Lekkas, Food Chemistry 108, 277 (2008).

[25] Otto Dvořák, Vlasta Charvátová, Research on dangerous effects of fire effluents from materials, Final research report, Prague: Sire Technical Institute (1999). 


\section{Figure captions}

Figure 1: Tube furnace decomposition and sampling apparatus according to DIN 53436 [10,25]: 1-furnace tube; 2-connecting adapter; 3-heating thermostat; 4-fume outlet; 5-mixing and measurement vessel; 6-dilutent secondary air inlet (not used in the present study); 7sampling line; 8-particle filters; 9-metering gas pump; 10-refrigerator; 11-CO, $\mathrm{CO}_{2}$ and $\mathrm{O}_{2}$ analyzers; $12-\mathrm{NO}_{2} / \mathrm{NO}$ converter; $13-\mathrm{SO}_{2}, \mathrm{NO}_{\mathrm{X}}$ and moisture analyzer; 14-exhaust outlet.

Figure 2: MIR and NIR spectra of the fumes from uncontrolled combustion of PET.

Figure 3: Comparison of the MIR and NIR spectra of fumes from controlled decomposition and combustion of PET at $500{ }^{\circ} \mathrm{C}$ and $800{ }^{\circ} \mathrm{C}$

Figure 4: Rotational-vibrational structure in methane and propane (stretching bands of C-H bonds)

Figure 5: The chromatogram of fumes from controlled decomposition of PET at $500{ }^{\circ} \mathrm{C}$

Figure 6: The chromatogram of fumes from controlled combustion of PET at $800{ }^{\circ} \mathrm{C}$

Figure 7: SIFT-MS spectrum obtained for fumes from controlled decomposition of PET at $500{ }^{\circ} \mathrm{C}$ using the $\mathrm{H}_{3} \mathrm{O}^{+}$reagent ion. The ion signal intensities are shown on a logarithmic scale in counts per second $(\mathrm{c} / \mathrm{s})$ as a function of the mass-to-charge ratios $(\mathrm{m} / \mathrm{z})$ of the ions. 
Table 1: The assignment of peaks from the gas chromatography

\begin{tabular}{|c|c|c|c|c|c|}
\hline \multirow{2}{*}{$\begin{array}{c}\text { Assig } \\
\text { n. }\end{array}$} & \multirow{2}{*}{$\begin{array}{c}\text { PET film - composition of fumes: } \\
\text { Name } \\
\end{array}$} & \multicolumn{2}{|c|}{$500{ }^{\circ} \mathrm{C}$} & \multicolumn{2}{|c|}{$800^{\circ} \mathrm{C}$} \\
\hline & & Area & Ratio & Area & Ratio \\
\hline 1 & Phenyl ethyne & & & 32.9 & 2.59 \\
\hline 2 & Xylene & 76.5 & 0.50 & & \\
\hline 3 & Styrene & 157 & 1.03 & 21.6 & 1.70 \\
\hline 4 & Benzaldehyde & 103 & 0.67 & 18.2 & 1.43 \\
\hline 5 & Phenol & 44 & 0.29 & 19 & 1.50 \\
\hline 6 & Indene & & & 22 & 1.73 \\
\hline 7 & Indane & 16 & 0.10 & & \\
\hline 8 & Phenylacetaldehyde & 20.3 & 0.13 & & \\
\hline 9 & Acetophenone & 44 & 0.29 & 29.8 & 2.35 \\
\hline 10 & Methylbenzoate & 24 & 0.16 & 6.5 & 0.51 \\
\hline 11 & Vinylbenzoate & 962 & 6.29 & 169 & 13.32 \\
\hline 12 & Benzoic acid & 4789 & 31.30 & 192 & 15.14 \\
\hline 13 & Naphthalene & 12,4 & 0.08 & 63.8 & 5.03 \\
\hline 14 & 4-methyl-benzoic acid & 343 & 2.24 & & \\
\hline 15 & 4-ethyl-benzoic acid, phenyl ester & 53.2 & 0.35 & & \\
\hline 16 & 4-ethyl-benzoic acid & 323 & 2.11 & & \\
\hline 17 & Biphenyl & 334 & 2.18 & 268 & 21.13 \\
\hline 18 & 3,4-dimethyl acetophenone & 350 & 2.29 & & \\
\hline 19 & Diphenylmethane & 8 & & 14.9 & 1.17 \\
\hline 20 & Biphenylene & & +2 & 23 & 1.81 \\
\hline 21 & Dibenzofurane & & 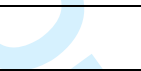 & 7.1 & 0.56 \\
\hline 22 & 6-methoxyquinoline-N-oxide & 553 & 3.61 & 18.4 & 1.45 \\
\hline 23 & $\begin{array}{l}\text { Phthalates (group of esters of phthalic and } \\
\text { terephthalic acids) }\end{array}$ & 5864 & 38.33 & 259 & 20.42 \\
\hline 24 & Terephthalic acids & 353 & 2.31 & & \\
\hline 25 & 9-fluorenone & 83 & 0.54 & & \\
\hline 26 & Anthracene & & & 40.2 & 3.17 \\
\hline 27 & 4-bifenyl carboxylic acid & 540 & 3.53 & 42.1 & 3.32 \\
\hline 28 & Pyrene & & & 3.8 & 0.30 \\
\hline 29 & Ethylene dibenzoate & 199 & 1.30 & 13.2 & 1.04 \\
\hline \multirow[t]{2}{*}{30} & 1,4-triphenyl & 55 & 0.36 & 4 & 0.32 \\
\hline & Footing: & 15298.4 & 100.00 & 1268.5 & 100.00 \\
\hline
\end{tabular}


Table 2. Main compounds identified in the SIFT-MS spectra of fumes of PET thermal decomposition and combustion at $500{ }^{\circ} \mathrm{C}$ and $800{ }^{\circ} \mathrm{C}$. For each compound, the stoichiometric formula is given together with its approximate molecular weight in $\mathrm{g} / \mathrm{mol}$, the precursor ions used for chemical ionization, the corresponding mass to charge ratio of the characteristic product ions and their concentrations in fumes analysed at atmospheric pressure in units of parts per million ppm.

\begin{tabular}{|c|c|c|c|c|c|c|}
\hline Name & Formula & $\begin{array}{c}\text { Molecula } \\
\text { r weight } \\
\text { g/mol } \\
\end{array}$ & $\begin{array}{l}\text { Precursor } \\
\text { Ions }\end{array}$ & $\begin{array}{c}\mathrm{m} / \mathrm{z} \text { of } \\
\text { product } \\
\text { ions }\end{array}$ & $\begin{array}{c}\text { ppm } \\
500{ }^{\circ} \mathrm{C}\end{array}$ & $\begin{array}{c}\text { ppm } \\
800{ }^{\circ} \mathrm{C}\end{array}$ \\
\hline Water & $\mathrm{H}_{2} \mathrm{O}$ & 18 & $\mathrm{H}_{3} \mathrm{O}^{+}$ & $19-37-55$ & 700 & 9000 \\
\hline Methane & $\mathrm{CH}_{4}$ & 16 & $\mathrm{O}_{2}^{+}$ & 47 & 600 & 15 \\
\hline Acetaldehyde & $\mathrm{C}_{2} \mathrm{H}_{4} \mathrm{O}$ & 44 & $\mathrm{H}_{3} \mathrm{O}^{+}$ & 45 & 90 & 8 \\
\hline Ethylene & $\mathrm{C}_{2} \mathrm{H}_{4}$ & 28 & $\mathbf{O}_{2}^{+}$ & 28 & 11 & 3 \\
\hline Formaldehyde & $\mathrm{CH}_{2} \mathrm{O}$ & 30 & $\mathrm{H}_{3} \mathrm{O}^{+}$ & 31 & 7 & 4 \\
\hline Methanol & $\mathrm{CH}_{4} \mathrm{O}$ & 32 & $\mathrm{H}_{3} \mathrm{O}^{+}$ & $33-51$ & 4 & 0.3 \\
\hline Acetone & $\mathrm{C}_{3} \mathrm{H}_{6} \mathrm{O}$ & 58 & $\begin{array}{l}\mathrm{H}_{3} \mathrm{O}^{+} \\
\mathbf{N O}^{+} \\
\mathrm{O}_{2}^{+}\end{array}$ & $\begin{array}{l}59-77 \\
\mathbf{8 8} \\
43-58\end{array}$ & 5 & 0.03 \\
\hline Benzene & $\mathrm{C}_{6} \mathrm{H}_{6}$ & 78 & $\begin{array}{l}\mathrm{H}_{3} \mathrm{O}^{+} \\
\mathrm{NO}^{+} \\
\mathbf{O}_{2}^{+}\end{array}$ & $\begin{array}{l}79 \\
78 \\
78\end{array}$ & 4 & 2 \\
\hline $\begin{array}{l}\text { Phthalates and } \\
\text { terephthalic } \\
\text { acid }\end{array}$ & $\overline{\mathrm{C}_{8} \mathrm{H}_{6} \mathrm{O}_{4}}$ & 166 & $\begin{array}{l}\mathrm{H}_{3} \mathbf{O}^{+} \\
\mathrm{NO}^{+} \\
\mathrm{O}_{2}^{+}\end{array}$ & $\begin{array}{l}149 \\
149 \\
149\end{array}$ & 1.4 & 0.7 \\
\hline Styrene & $\mathrm{C}_{8} \mathrm{H}_{8}$ & 104 & $\begin{array}{l}\mathrm{H}_{3} \mathrm{O}^{+} \\
\mathrm{NO}^{+} \\
\mathrm{O}_{2}^{+}\end{array}$ & $\begin{array}{l}105 \\
104 \\
104\end{array}$ & 0.8 & 0.5 \\
\hline Ethanol & $\mathrm{C}_{2} \mathrm{H}_{6} \mathrm{O}$ & 46 & $\mathrm{H}_{3} \mathrm{O}^{+}$ & 47 & 0.6 & 0.3 \\
\hline Toluene & $\mathrm{C}_{7} \mathrm{H}_{8}$ & 92 & $\begin{array}{l}\mathrm{H}_{3} \mathrm{O}^{+} \\
\mathrm{NO}^{+} \\
\mathrm{O}_{2}^{+}\end{array}$ & $\begin{array}{l}93 \\
92 \\
92\end{array}$ & 0.5 & 0.1 \\
\hline $\begin{array}{l}\text { Xylene, } \\
\text { ethylbenzene }\end{array}$ & $\mathrm{C}_{8} \mathrm{H}_{10}$ & 106 & $\begin{array}{l}\mathrm{H}_{3} \mathrm{O}^{+} \\
\mathrm{NO}^{+} \\
\mathrm{O}_{2}^{+}\end{array}$ & $\begin{array}{l}107 \\
106 \\
106\end{array}$ & 0.5 & 0.2 \\
\hline Naphthalene & $\mathrm{C}_{10} \mathrm{H}_{8}$ & 128 & $\begin{array}{l}\mathrm{H}_{3} \mathbf{O}^{+} \\
\mathrm{NO}^{+} \\
\mathrm{O}_{2}^{+}\end{array}$ & $\begin{array}{l}129 \\
128 \\
128\end{array}$ & 0.2 & 0.4 \\
\hline Biphenyl & $\mathrm{C}_{12} \mathrm{H}_{10}$ & 154 & $\begin{array}{l}\mathrm{H}_{3} \mathrm{O}^{+} \\
\mathrm{NO}^{+} \\
\mathrm{O}_{2}^{+}\end{array}$ & $\begin{array}{l}155 \\
154 \\
154\end{array}$ & 0.05 & 0.08 \\
\hline Phenol & $\mathrm{C}_{6} \mathrm{H}_{6} \mathrm{O}$ & 94 & $\mathrm{H}_{3} \mathrm{O}^{+}$ & 95 & 0 & 0.7 \\
\hline
\end{tabular}




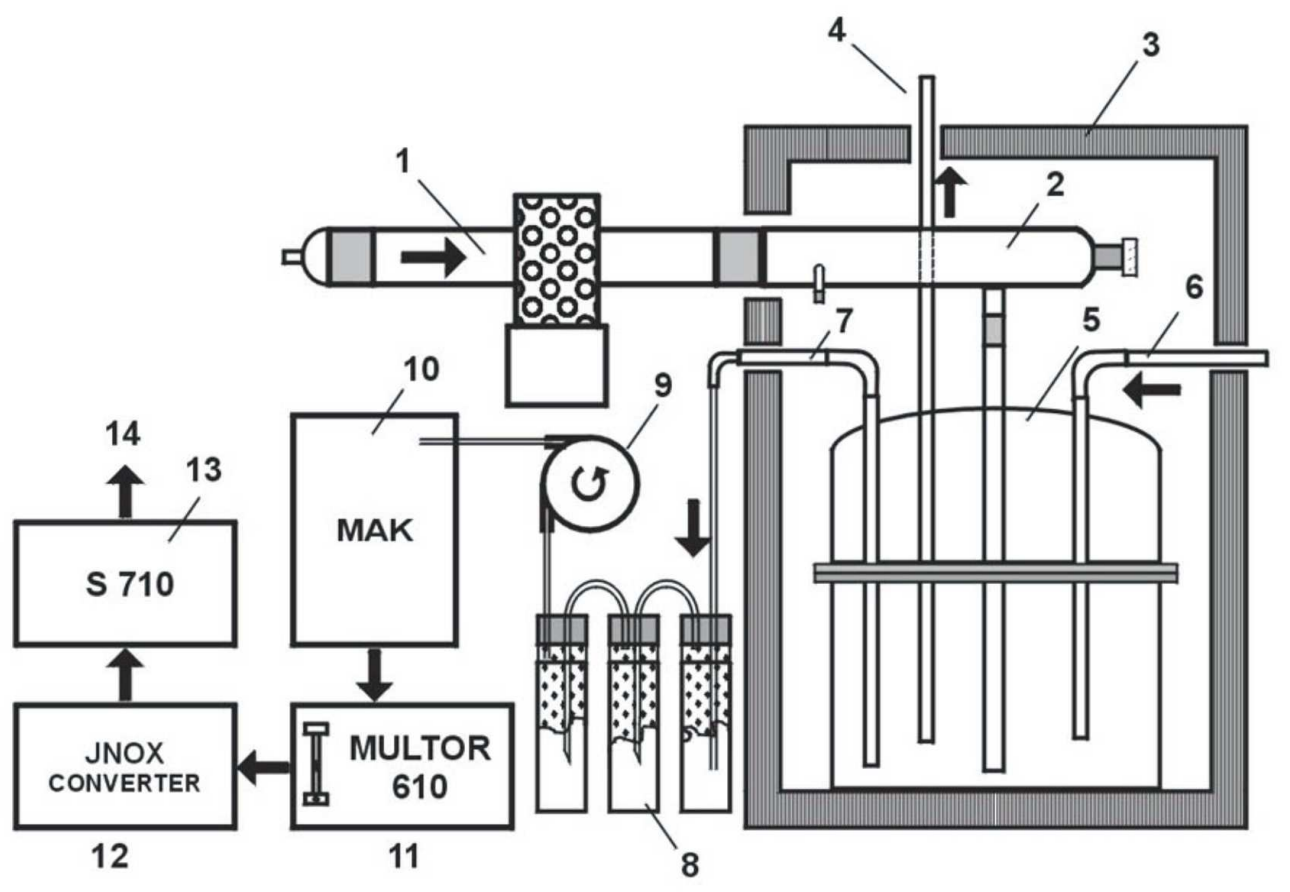

$259 \times 180 \mathrm{~mm}(500 \times 500 \mathrm{DPI})$ 


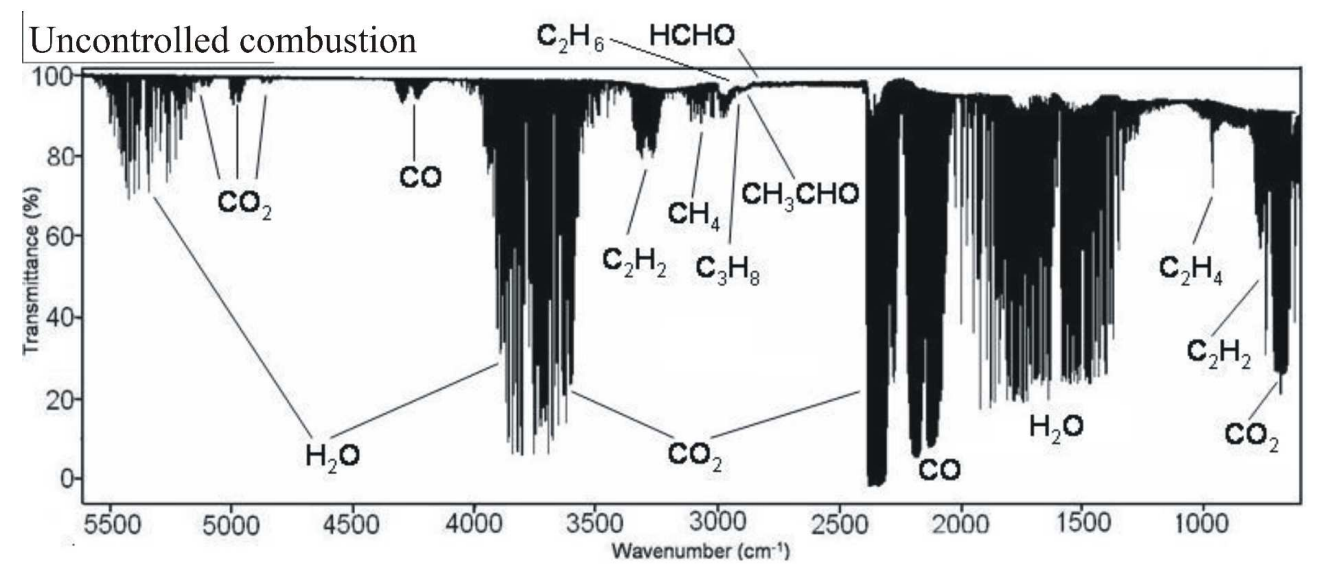

$289 \times 124 \mathrm{~mm}(500 \times 500 \mathrm{DPI})$ 

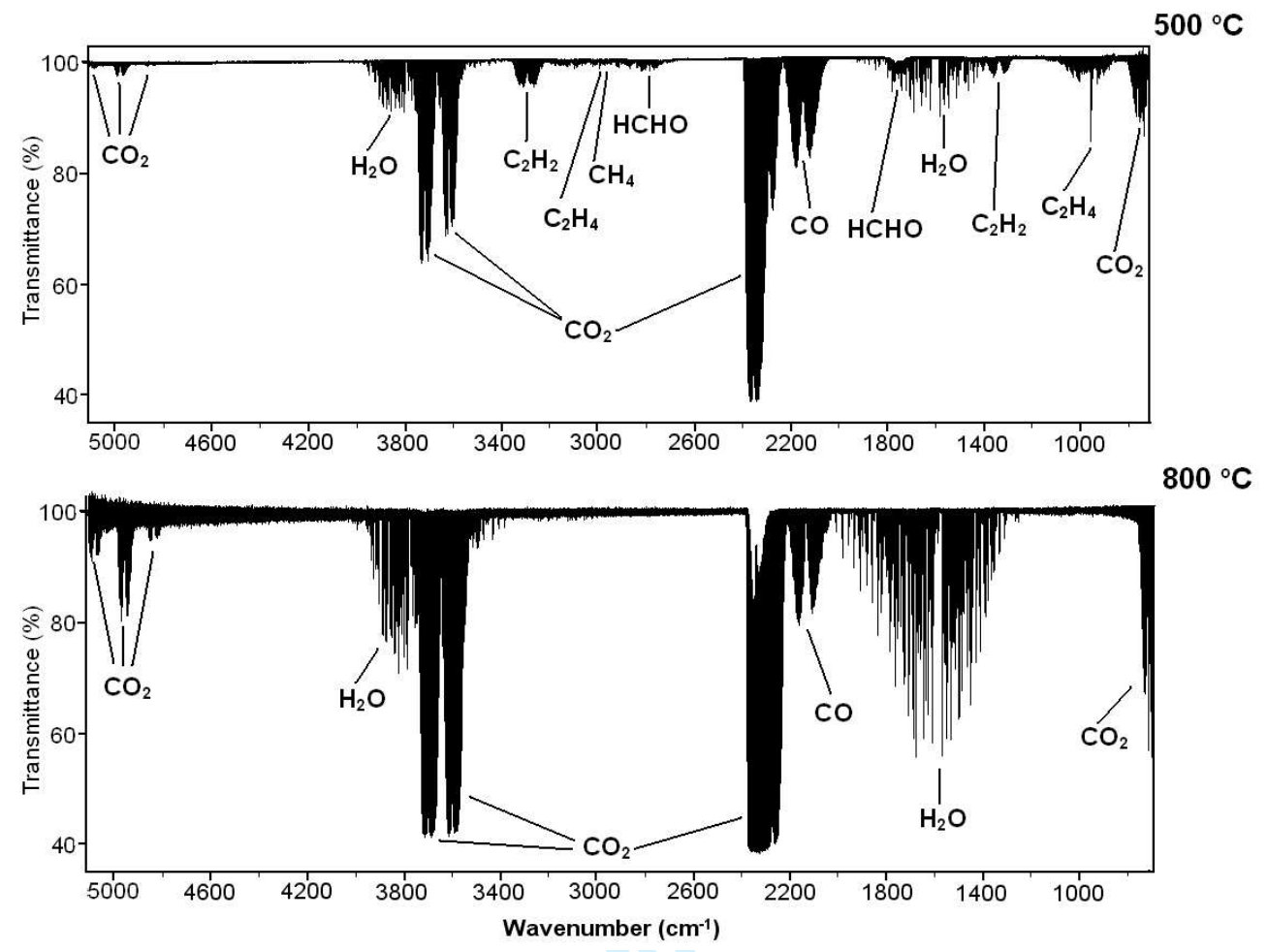


\section{Methane std}
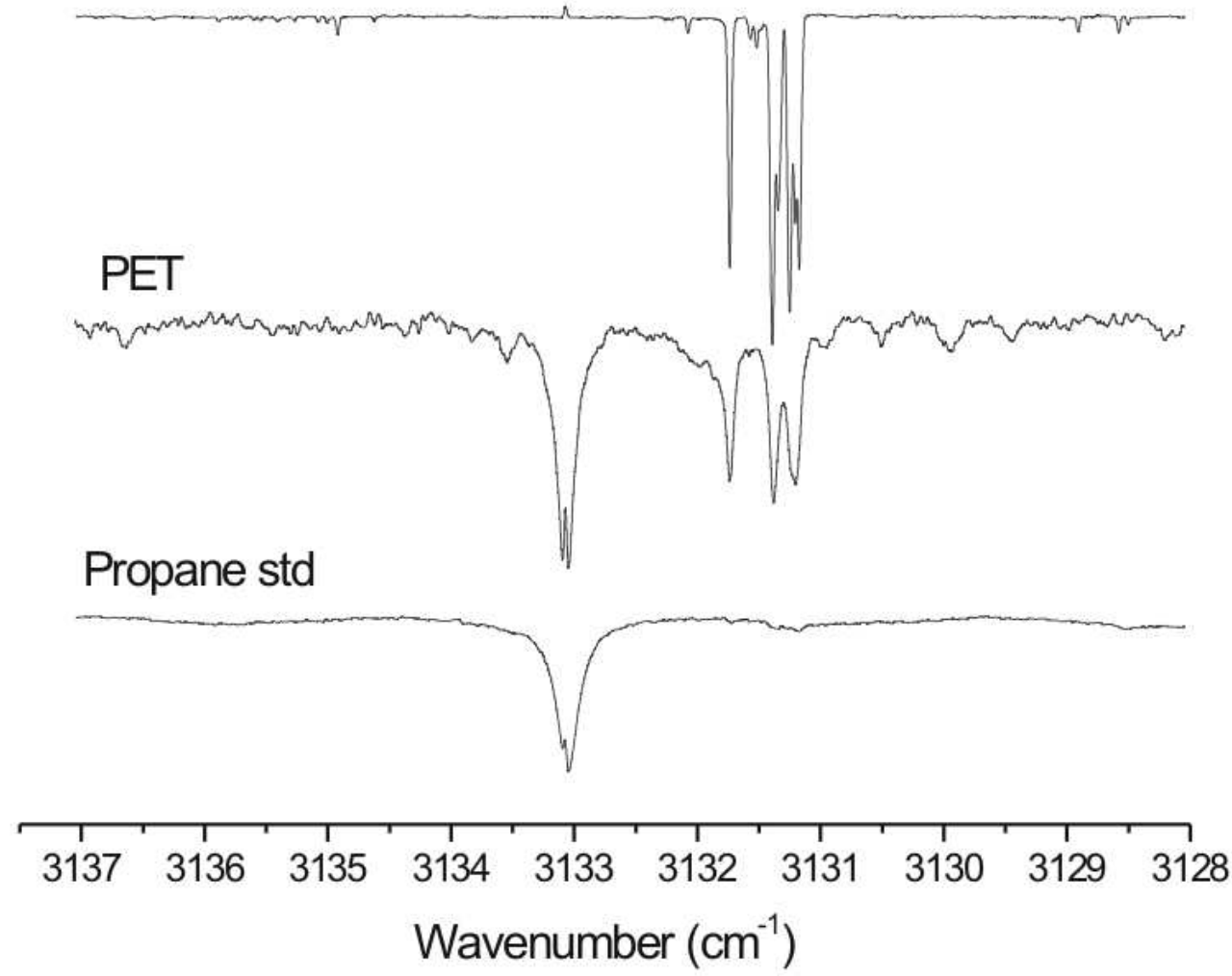

$38 \times 35 \mathrm{~mm}(500 \times 500 \mathrm{DPI})$ 


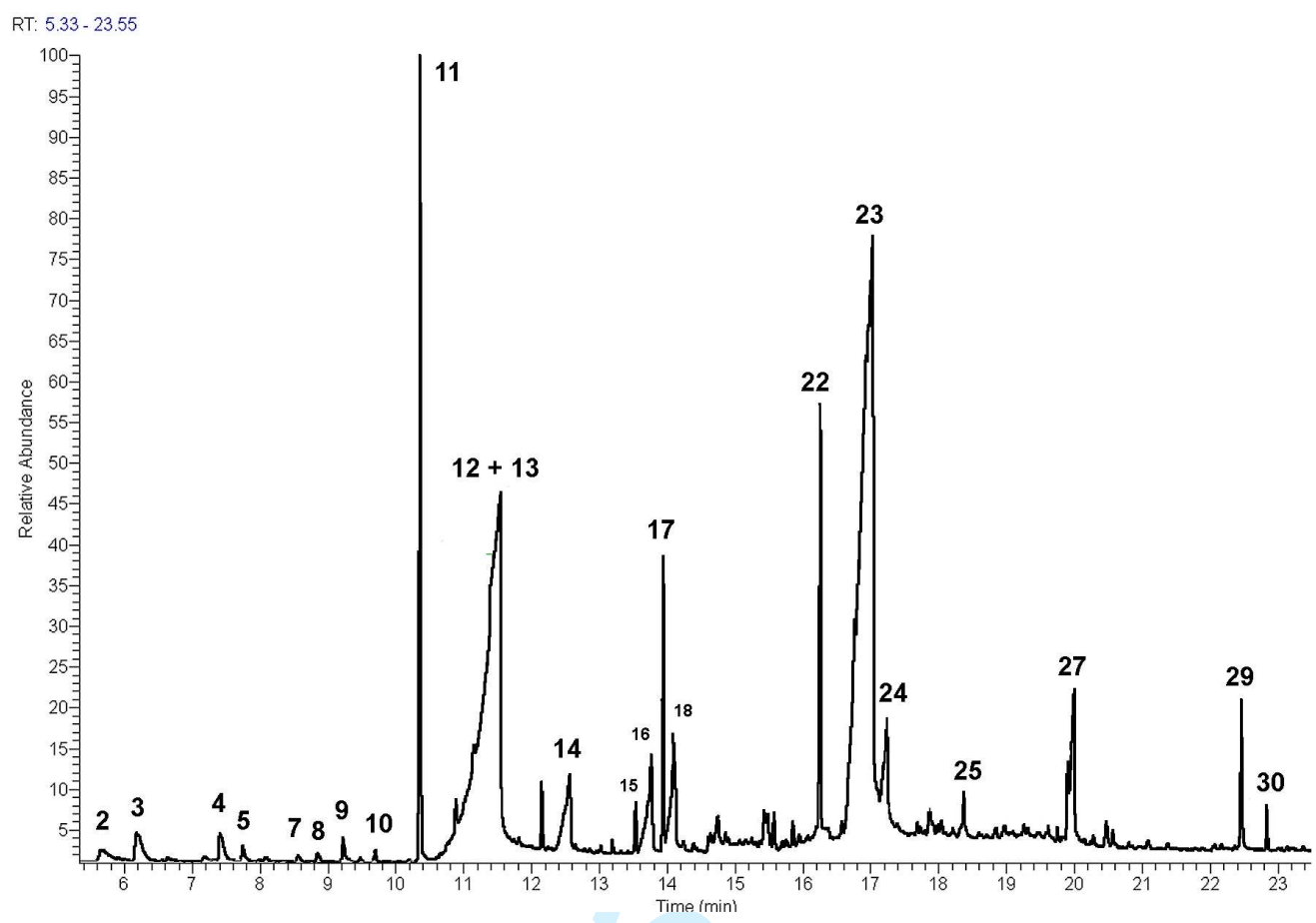

30

31

32

33

34

35

36

37

38

39

40

41

42

43

44

45

46

47

48

49

50

51

52

53

54

55

56

57

58

59

60

URL: http://mc.manuscriptcentral.com/tandf/tmph 


1
2
3
4
5
6
7
8
9
10
11
12
13
14
15
16
17
18
19
20
21
22
23
24
25
26
27
28
29
30
31
32
33
34
35
36
37
38
39
40
41
42
43
40
45
49
50
51
52
53
55
50

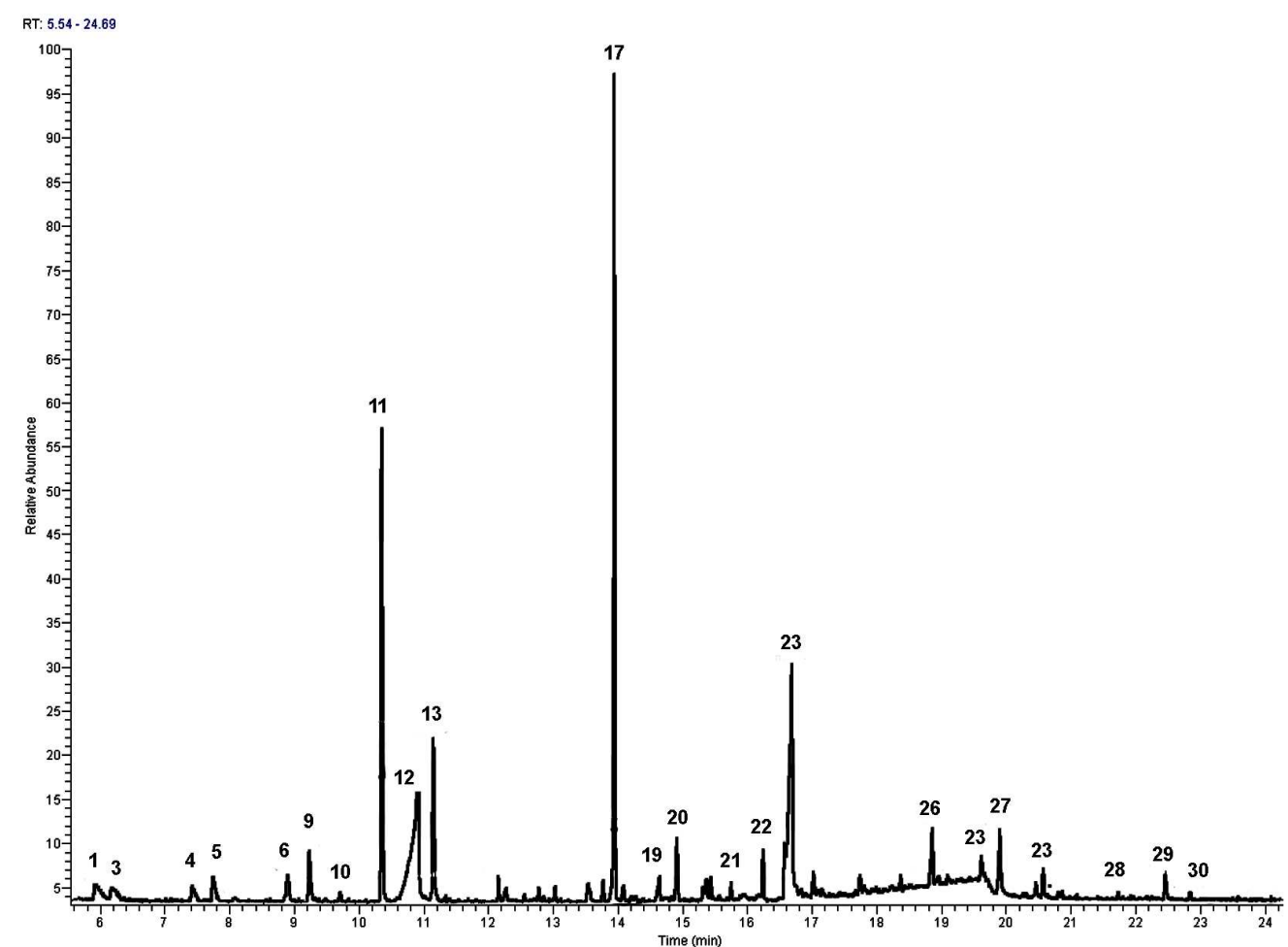

URL: http://mc.manuscriptcentral.com/tandf/tmph 


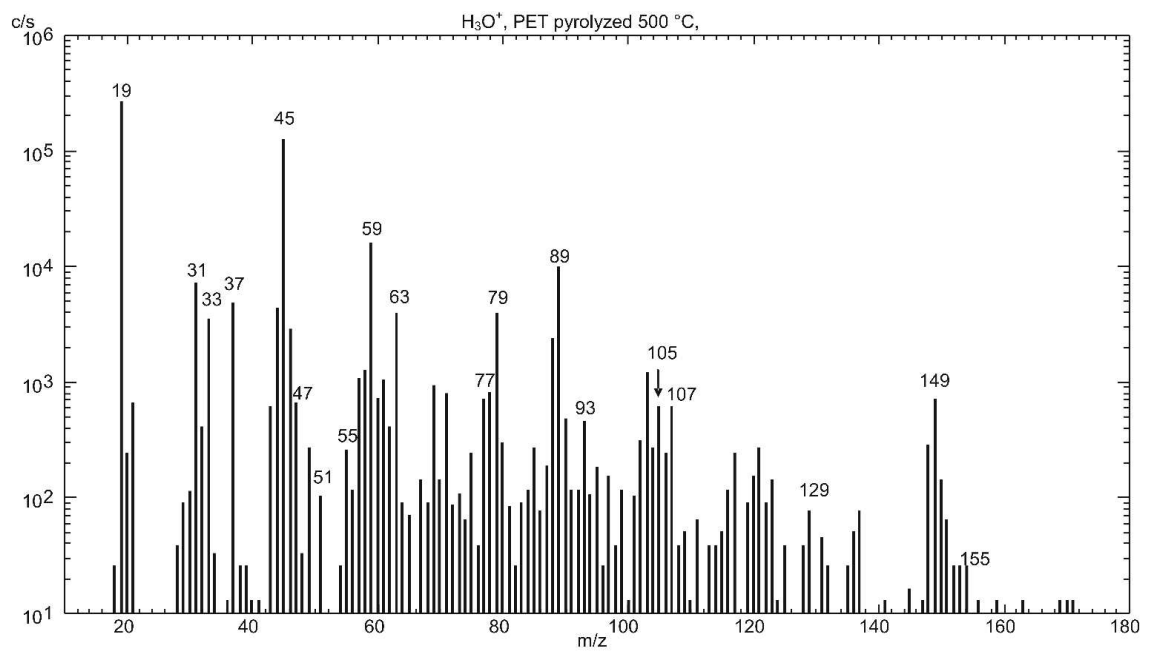

$446 \times 221 \mathrm{~mm}(500 \times 500 \mathrm{DPI})$ 